\title{
1 LEACHING BEHAVIOUR OF HAZARDOUS WASTE UNDER THE IMPACT 2 OF DIFFERENT AMBIENT CONDITIONS.
}

3

4 Isabella Pecorini ${ }^{\mathrm{a}, *}$, Francesco Baldi ${ }^{\mathrm{a}}$, Donata Bacchi ${ }^{\mathrm{a}}$, Ennio Antonio Carnevale ${ }^{\mathrm{a}}$, $5 \quad$ Andrea Corti ${ }^{\mathrm{b}}$

$6{ }^{\mathrm{a}}$ DIEF, Department of Industrial Engineering, University of Florence, via Santa Marta

7 3, 50139 Florence, Italy

$8{ }^{b}$ DIISM, Department of Information Engineering and Mathematic, University of Siena, 9 via Roma 56, 56100 Siena, Italy

\section{ABSTRACT}

12 The overall objective of this study is to provide an improved basis for the assessment

13 of the leaching behaviour of waste marked as hazardous partly stabilised (European

14 waste catalogue code $190304 *$ ). Four samples of hazardous partly stabilised waste

15 were subjected to two leaching tests: up-flow column tests and batch equilibrium tests.

16 The research was carried out in two directions: the first aims at comparing the results of

17 the two experimental setups while the second aims at assessing the impact of different

Abbreviations: DOC, dissolved organic carbon; L/S, liquid to solid ratio; LOD, limit of detection; PCA, principal component analysis; TOC, total organic carbon; TS, total solids; TVS, total volatile solids; WHPS, waste marked as hazardous partly stabilized.

* Corresponding author at: University of Florence, DIEF - Department of Industrial Engineering of Florence, Florence, Italy. Tel.: +39 0552758718.

E-mail address: isabella.pecorini@unifi.it (I. Pecorini). 
18 ambient conditions on the leaching behaviour of waste. Concerning this latter objective

19 the effect of mesophilic temperature, mechanical constraints and acid environment were

20 tested through column percolation tests. Results showed no significant differences

21 between batch and column leaching test outcomes when comparing average

22 concentrations calculated at a liquid to solid ratio of $101 \cdot \mathrm{kg}^{-1} \mathrm{TS}$. Among the tested

23 ambient conditions, the presence of an acid environment ( $\mathrm{pH} 4.5$ ) accelerated the

24 leaching process resulting in a higher cumulative released quantity measured on the

25 majority of the investigated polluting substances. On the contrary, the effect of

26 temperature and mechanical constraints seemed to not affect the process showing final

27 contents even lower than values found for the standard test. This result was furthermore

28 confirmed by the application of the principal component analysis. Column tests

29 represent an effective tool for assessing environmental impact over time finding peak

30 concentrations in the early stages of the elution process that batch tests are not able to

31 detect. Nevertheless, column tests are time-consuming and batch tests can be a valuable

32 alternative when time is a constraint.

33

34 Keywords: Hazardous Waste; Leachate; Column Leaching Test; Batch Leaching Test;

35 Landfilling; Partly Stabilised Waste.

36

37 1. Introduction 
39 In 2013, more than 1 million tons of hazardous waste were disposed in Italian

40 landfills (ISPRA, 2015). In order to provide environmental protection, the disposal of 41 hazardous waste in landfill is governed by National and European legislations

42 (European Council Decision 2003/33/EC of 19 December 2002) that set strict criteria to

43 be fulfilled. Hazardous waste can be disposed in underground storage or in landfills in

44 accordance with the acceptance criteria or due to derogations of the limit values (e.g.

45 inorganic elements, total organic carbon, dissolved organic carbon). In particular,

46 hazardous waste can be disposed in non-hazardous landfills if stable and non-reactive.

47 Considering the definition provided by the European Council (2002), stable and non-

48 reactive means that the leaching behaviour of waste do not change adversely in the

49 long-term under landfill design conditions or foreseeable accidents as the impact of

50 ambient conditions: e.g. temperature, mechanical constraints, etc..

51 Waste marked as Hazardous Partly Stabilised (WHPS, European waste catalogue 52 code $190304 *$ ) are solidified/stabilised waste that after the stabilisation process can 53 release dangerous constituents which have not been changed completely into non54 dangerous in the short, middle or long term (EPA, 2002). The composition of WHPS is 55 strongly heterogeneous including hazardous waste from waste processing facilities (e.g. 56 fly and bottom ashes from incinerators) or wastewater treatment plants (e.g. industrial 57 sludge). As a consequence, their chemical characteristics are also heterogeneous and 
58 their disposal scenarios concern several possibilities such as underground storage or 59 even non-hazardous landfills in compliance with the acceptance criteria or their 60 derogations. Nevertheless, in accordance with their characteristics, the elution process 61 of this category of waste is not easy to predict and their acceptance in hazardous or non62 hazardous landfills may be source of environmental risk due to the uncertainty of the 63 release of polluting substances over time. As such, a deep understanding of the release 64 of contaminants upon contact with water and under different landfill conditions 65 (European Council, 2002) is of prime importance in order to investigate the stability of 66 WHPS .

67 The release of soluble substances into water phase is the result of several phenomena 68 that can occur simultaneously depending on leaching conditions, properties of the solid 69 matrix and physic-chemical processes (Batchelor, 2006). Leaching tests are common 70 tools for assessing constituent release upon contact with water (Lopez Meza et al., 71 2008). According to Harwell (1999), leaching tests can be divided into two general 72 categories: static and dynamic extraction tests. In static extraction protocols (batch 73 tests), leaching takes place with a single volume of leachant while in dynamic extraction 74 protocols, the leaching fluid is renewed throughout the test.

75 Batch equilibrium tests typically consists of contacting a sub-sample of material with 76 a liquid phase in order to establish pseudo-equilibrium conditions. Once equilibrium is 77 established, release is dependent on the geochemistry of the solid phase and on the 
78 chemistry of the liquid phase rather than on contact time (Garrabrants and Kosson, 79 2005).

80 Dynamic extraction tests provide information about the kinetics of contaminant 81 mobilization and results are presented as a function of time. Among dynamic extraction 82 tests, flow-through tests (e.g. column tests) are used to obtain information on short and 83 long term leaching behaviour (Butcher et al., 1996). Water is percolated through a 84 column of material and collected as a function of liquid to solid ratio (L/S), which is 85 used to represent leaching time. Flow-through leaching test methods can be used to 86 simulate the leaching process of wastes disposed under particular landfill conditions.

87 For example when waste is more permeable than its surrounding materials or when it 88 has degraded under various environmental stresses to a state that ground water can 89 flow-through the waste via the porosity system of the waste matrix (Poon and Chen, 90 1999). In this case, when the leachant flows through the waste, it carries away the 91 mobile fraction of the contaminants. At the same time the immobile fraction is 92 continuously solubilized to re-establish the equilibrium. The leachant flowing via the 93 porosity system of the solid waste matrix carries away the mobile fraction and causes a 94 contaminant concentration gradient which accelerates the leaching process. Because of 95 its ability to accelerate the leaching process the flow-through leaching test methods can 96 be used to study the long term leaching performance of waste (Poon and Chen, 1999). 
97 In compliance with the standard methods EN 12457, $2002\left(\mathrm{~L} / \mathrm{S}=101 \cdot \mathrm{kg}^{-1} \mathrm{TS}\right)$ and

98 CEN TS 14405, $2015\left(\mathrm{~L} / \mathrm{S}=0.11 \cdot \mathrm{kg}^{-1} \mathrm{TS}\right)$, batch equilibrium tests and percolation tests

99 are acquired by the European Council Decision of 19 December 2002 as criteria for 100 acceptance of hazardous waste in landfill.

101 When comparing batch and column tests, batch experiments offer the advantage of 102 easier design, while column testing provides an optimum approximation to leaching 103 processes that occur under field conditions without compromising reproducibility of 104 experiments (Butera et al., 2015; Delay et al., 2007; Dijkstra et al., 2006). Column tests 105 are more suitable for prediction purposes, but they are often time-consuming, reaching 106 duration of several weeks. Alternatively, batch tests can be carried out in shorter periods 107 of time, varying from several hours to few days. In the light of the practical advantages 108 and disadvantages, it is important to understand the similarities and differences between 109 constituent leaching under batch and column tests with the aim to provide effective 110 tools for environmental decision-making (Lopez Meza et al., 2008).

111 Several researches have been performed on various waste categories aim to study the 112 leaching behaviour by means of batch and column tests: stabilised/solidified waste 113 (Barna et al., 1997; De Windt et al., 2007; Liu et al., 2013; Malviya and Chaudhary, 114 2006; Poon et al., 2001), mining waste (Al-Abed et al., 2008; Turner et al., 2009), 115 construction and demolition waste (Butera et al., 2014; Butera et al., 2015; Delay et al., 116 2007; Lopez Meza et al., 2008; Nielsen et al., 2006; Roussat et al., 2008), contaminated 
117 soils (Cruz Payán et al., 2012; Gardner et al., 2007; Hartley et al., 2004), fly-ash

118 stabilised soils (Bin-Shafique et al., 2006), soils used in construction works

119 (Quaghebeur et al., 2006). To our knowledge, the leaching behaviour of WHPS and its

120 alteration to foreseeable landfill conditions has not yet been studied.

121 The overall objective of this study is therefore to provide an improved basis for the 122 assessment of constituent release from WHPS. Four WHPS samples obtained from

123 different waste treatment facilities in Tuscany (Italy) were subjected to both batch

124 equilibrium and up-flow column tests and evaluated in relation to: differences between

125 column and leaching test in the release of polluting substances and the impact of

126 different ambient conditions on the leaching behaviour (temperature, mechanical 127 constraints and acid environment).

128

129 2. Materials and methods

130

1312.1 Materials

132 Four WHPS samples (W1, W2, W3 and W4 - European Waste Code 1903 04*)

133 were obtained from four different treatment facilities in Tuscany (Italy). WHPS samples

134 were selected based on easy procurement of the waste and according to chemical

135 analysis with the intent to study a significant range of cases. According to the

136 description of the production process provided by the facility operators, W1-W4 were 
137 obtained after a solidification/stabilization treatment of hazardous and non-hazardous 138 waste. In particular W1-W4 were composed by: fly ashes containing dangerous 139 substances $(1901$ 13*), bottom ashes and slags containing dangerous substances (19 01

$\left.14011^{*}\right)$, filter cakes from gas treatment (19 01 05*), soil and stones containing dangerous 141 substances $\left(\begin{array}{lll}17 & 05 & 03 *\end{array}\right)$, solid wastes from gas treatment containing dangerous 142 substances $\left(100207^{*}\right)$, sludge from treatment of urban waste water (19 0805$)$, sludge

143 from biological treatment of industrial waste $\left(\begin{array}{lll}19 & 08 & 12\end{array}\right)$ and sludge containing 144 dangerous substances from biological treatment of industrial waste water (19 $0811^{*}$ ).

145 The hydraulic binders used for the treatment were lime and Portland cement. The 146 sampling was done in compliance with the standard procedure EN 932-1 (1996): sample

147 increments were collected from different positions in the stockpiles by means of a 148 shovel and combined into primary samples (approximately $20 \mathrm{~kg}$ ) which were 149 transported to the laboratory by means of sealed plastic drums. Sub-samples (test 150 portions) of each of the primary samples were then used for leaching tests. A summary

151 of the physico-chemical characteristics is provided in Table 1.

152 Here Table 1.

153

1542.2 Batch leaching test and column leaching tests at standard conditions

155 Two types of leaching were in focus: batch equilibrium tests and up-flow saturated 156 columns. 
157 Batch equilibrium tests were carried out according to EN 12457-2 (2002) standard 158 test for materials with particle size dimensions $<4 \mathrm{~mm}$ and by using a $\mathrm{L} / \mathrm{S}$ of $101 \mathrm{~kg}^{-}$ $159{ }^{1} \mathrm{TS}$.

160 Up-flow column leaching tests with demineralized water as leaching agent 161 (conductivity of $1 \mathrm{mS} \cdot \mathrm{m}^{-1}$ ) were carried out according to CEN TS 14405 (2014) with 162 modification of the column dimensions. Columns made of plastic (PTFE) with a base of $163115.2 \mathrm{~cm}^{2}$ and a volume of $1920 \mathrm{ml}$ were used. The sample packing procedure was 164 carried out firstly fitting the bottom section with a layer of approximately $1 \mathrm{~cm}$ of fine165 grained inert material. The column was then filled with the test sample in five 166 consecutive layers that were packed by using a weight of $0.5 \mathrm{~kg}$ dropping it three times.

167 The weight felt down $20 \mathrm{~cm}$ along a rod used as guide. Finally the top section of the 168 column was fit with another layer of approximately $1 \mathrm{~cm}$ of fine-grained inert material.

169 The dry mass $\left(\mathrm{m}_{0}\right)$ of the sample was determined in accordance with the mass of the 170 sample and total solids (TS) data. Based on the volume of the column, density was also 171 calculated.

172 The test was started after having saturated the column with the leaching agent using a 173 peristaltic pump (FH10, Thermo Scientific, Italy). In order to equilibrate the system, the 174 saturated material was left in static conditions (without flow rate) for a period of three 175 days. To verify equilibrium conditions at the outlet of the column, $\mathrm{pH}$ was measured on 176 a first small portion of eluate $(15 \mathrm{ml})$ and on the first collected fraction. The system was 
177 assumed in equilibrium if the $\mathrm{pH}$ values measured in the two portions of eluate do not 178 deviate more than $0.5 \mathrm{pH}$ unit. After the equilibrium period, the upwards flow rate was 179 set at $72.1 \mathrm{ml} \cdot \mathrm{h}^{-1}$ which corresponds to a linear velocity of $15 \mathrm{~cm} \cdot \mathrm{d}^{-1}$. Tests were 180 performed until a $\mathrm{L} / \mathrm{S}$ of $101 \cdot \mathrm{kg}^{-1} \mathrm{TS}$ was reached. During the experiment seven eluate 181 fractions $i$ were collected at predefined intervals $\left(i: 0.1,0.2,0.5,1,2,5\right.$ and $\left.101 \cdot \mathrm{kg}^{-1} \mathrm{TS}\right)$.

182 Each fraction was then filtered through a membrane with a pore size dimension of 0.45 $183 \mu \mathrm{m}$ and stored in sealed bottles before analysis.

184 For each component the quantities released in all eluate fractions were calculated as 185 in eq. 1 :

$$
U_{i}=\frac{\left(V_{i} \cdot c_{i}\right)}{m_{0}}
$$

186 where:

$188 i$ : index of the eluate fraction $(\mathrm{L} / \mathrm{S}=0.1,0.2, \ldots, 10)$;

$189 U_{i}$ : released quantity of a component per quantity of sample in the eluate fraction $i$ $190 \quad\left(\mathrm{mg} \cdot \mathrm{kg}^{-1} \mathrm{TS}\right)$

$191 V_{i}$ : volume of the eluate fraction $i(1)$;

$192 c_{i}$ : concentration of the component concerned in the eluate fraction $i\left(\mathrm{mg} \cdot \mathrm{l}^{-1}\right)$;

$193 m_{0}$ : dry mass of the test portion ( $\left.\mathrm{kgTS}\right)$.

195 When the concentration of a component resulted lower than the limit of detection 
196 (LOD), the upper limit of $U_{i}$ was calculated by making $c_{i}$ equal to the LOD (CEN TS

197 14405, 2014). For each specific component the cumulative released quantity was

198 calculated by accumulating the released quantities measured in the different eluate

199 fractions $\left(U_{i}\right)$.

200 The parameters analysed in the eluates belong to the list set by European Council

201 (2002) for the acceptance criteria of hazardous and non-hazardous in landfills (leaching

202 limit values). The investigated parameters were selected based on statistical

203 significance. In particular, components were not analysed if after performing the batch

204 equilibrium test they were found under the LOD for at least the half of the investigated

205 samples. As such, the concentration of DOC (dissolved organic carbon) was measured

206 in accordance with APAT (2003) method; the concentrations of $\mathrm{Cr}, \mathrm{Cu}, \mathrm{Ni}, \mathrm{Zn}$ by using

207 EPA 6020A (2007); sulphates and chlorides by using EPA 9056A (2007); pH by using

208 APHA (2006).

209

$210 \quad 2.3$ Column leaching tests assessing ambient conditions

211 In order to evaluate the impact of ambient conditions on the leaching behaviour of

212 WHPS, column leaching tests were performed on W1 and W2 by assessing mechanical

213 constraints, temperature and acid environment. The results of these tests were compared

214 with the results obtained through the application of the standard protocol (used as blank

215 assay). W1 and W2 were selected among the tested samples as cases of high 
216 contamination (W1) and low contamination (W2). Column leaching tests were preferred

217 to batch equilibrium tests for their capability of investigating the leaching behaviour and

218 thus the stability of waste over time. Temperature and mechanical constraints were

219 studied following the indications of the European Council (2002). Even if the landfill

220 body is mostly characterized by alkaline environment, acid conditions were studied ad

221 absurdum as a critical aspect that can accelerate the elution process (Du et al., 2012; Liu

222 et al., 2013).

223 The mechanical constraint effect was obtained replying five times the packing

224 procedure used for the standard test. In this case a weight of $1 \mathrm{~kg}$ was used. This

225 operation provided an increase of density inside the column of approximately $15 \%$ for

226 both waste. In order to contextualise this phenomenon with field conditions, the increase

227 of density occurs inside the landfill body in relation to an increase of depth and effective

228 stress (Beaven, 2000).

229 The temperature effect was assessed warming the leachant up to $40^{\circ} \mathrm{C}$. This

230 temperature can be reached inside the landfill body under mesophilic conditions (Raga

231 and Cossu, 2013; Tong et al., 2015; Wang et al., 2012). The column was furthermore

232 enveloped with an heating coil where water at $40^{\circ} \mathrm{C}$ was continuously passed through.

233 In order to avoid heat dispersion the system was rolled with an insulation material.

234 Leachant temperature was continuously heated by means of an immersion thermostat

235 heater (Fa 90, Falc Instruments, Italy). 
236 Several studies evaluated the leaching behaviour of waste under acid leachant (Baba 237 et al., 2008; Cruz Payán et al., 2012; Hartley et al., 2004; Liu et al., 2013). In the present

238 research acid conditions were assessed performing the column leaching test by using 239 acidified demineralised water as leaching agent. In particular, demineralised water was 240 acidified to $\mathrm{pH} 4.5$ with concentrated nitric acid, $\mathrm{HNO}_{3}$ (Du et al., 2012).

\section{3. Results and discussion}

\subsection{Comparison between leaching tests}

Considering column test results, Fig. 1 represents the cumulative trends of W1-W4

246 (expressed in terms of $\mathrm{mg} \cdot \mathrm{kg}^{-1} \mathrm{TS}$ ) as function of $\mathrm{L} / \mathrm{S}$. The analysed constituents showed 247 similar behaviours over time. In particular two different phases were determined. The 248 first phase was characterized by a deep mobilisation of the constituents. This step is 249 represented by a high slope of the cumulative curves and it is generally associated with 250 the first five fractions, until the $\mathrm{L} / \mathrm{S}=21 \cdot \mathrm{kg}-1 \mathrm{TS}$. As demonstrated by Delay et al., 2007, 251 in this phase, dissolution and surface wash-off processes play a dominant role. The 252 second phase was characterized by a lower slope of the curve. The trends tended 253 towards a horizontal asymptote with the increase of L/S. As reported by other studies 254 (Kalbe et al., 2008; Simon et al., 2008), the depletion of soluble components leads to 255 lower concentrations in the eluates over time until steady state conditions are reached. 
256 Different trends were found for $\mathrm{Zn}$ for $\mathrm{W} 2, \mathrm{Cu}$ and Ni for W4 and for sulphates in 257 general. In these cases high concentrations of the contaminant were still persistent in the 258 last collected fractions determining a slow release of the component over time. Anyway, 259 a slight decreasing trend was also observed after the fourth/fifth fraction.

$260 \quad$ Here Figure 1.

261

262 With the aim of comparing batch and column tests, if batch test concentrations $\left(c_{i, b}\right)$ 263 are compared with column eluates at the same $L / S=i$ the main outcome is an 264 overestimation of the static method (Delay et al., 2007). This is explained by the fact 265 that while in batch tests the eluent is in continuous contact with the material, in column 266 tests the elution agent is constantly renewed. As such $c_{i, b}$ were compared with an 267 average concentration $\rho_{i}$ calculated for column leaching tests as proposed by Delay et al. 268 (2007). In particular, $\rho_{i}\left(\mathrm{mg} \cdot \mathrm{l}^{-1}\right)$ is determined by the ratio between the total released 269 amount of a constituent (expressed in $\mathrm{mg}$ ) and the total elution volume (expressed in 1) 270 at a given $L / S=i$ (eq. 2 ).

$$
\rho_{i}=\frac{m_{0} \cdot \sum_{i=0.1}^{i} U_{i}}{\sum_{i=0.1}^{i} V_{i}}
$$

271 Considering DOC results, the calculated average concentrations at a L/S of $10 \mathrm{l} \cdot \mathrm{kg}^{-1}$ $272 \rho_{10}(738 \mathrm{mg} / 1,45 \mathrm{mg} / 1,429 \mathrm{mg} / \mathrm{l}$ and $210 \mathrm{mg} / \mathrm{l}$ for W1, W2, W3 and W4 respectively), 273 were found comparable to $c_{10, b}$ (measured to be $656 \mathrm{mg} / 1,50 \mathrm{mg} / 1,316 \mathrm{mg} / \mathrm{l}$ and 152 
$274 \mathrm{mg} / \mathrm{l})$. This result was found valid for each of the tested constituents. In order to verify

275 the agreement between batch test results and $\rho_{10}$ a Welch's t-test was applied for each of

276 the tested components to identify significant differences between the two statistical

277 populations. Under this perspective, Tab. 2 and Fig.2 provide a comparison between $c_{10}$

278 and $\rho_{\mathrm{av}, 10}$. In particular the ratio $c_{10, b} / \rho_{10}$ and its inverse were also analysed (values $>1$

279 indicate overestimation of the batch test, values $<1$ indicate underestimation).

$280 \quad$ Here Table 2.

$281 \quad$ Here Figure 2.

282

283 The two values were generally in agreement, with differences of less than a factor of 284 two for the $90 \%$ of the measured elements. This outcome is comparable to the findings 285 achieved by Butera et al., 2015 for the comparison of column and lysimeter 286 experiments. The result was furthermore confirmed by the application of the Welch t287 test which underlined that statistically differences were not found between the two data 288 sets $(p>0.05)$. Differences between the two methods were found only for W2 which is 289 characterized by low concentrations, measured even below the LOD for $\mathrm{Cu}$ and $\mathrm{Ni}$.

290 In general column tests represent an effective tool for assessing environmental 291 impact over time. In particular, WHPS present a high release of constituents in the first 292 stage of the elution process while with the increase of L/S and the depletion of soluble 293 substances the leaching behaviour seems to tend towards an horizontal asymptote. 
294 These results are concurring with the findings of Lopez Meza et al. (2008) for other 295 granular waste (bottom ashes, fly ashes, construction debris and laboratory formulated 296 concrete), Delay et al. (2007) and Nielsen et al. (2006) for demolition waste,

297 Quaghebeur et al. (2006) for soils and Bin-Shafique et al. (2006) for fly-ash stabilised 298 soils. Anyway, batch equilibrium tests are valuable tools in order to give a first 299 indication on the leaching behaviour of WHPS resulting in a good approximation with 300 the average concentration leached over time.

\subsection{Comparison between different ambient conditions}

303 In order to investigate the impact of ambient conditions, column tests were preferred 304 to batch tests due to their peculiarity to analyse the leaching behaviour over time. As 305 such, mechanical constraints (C), temperature (T) and acid environment (A) were 306 evaluated. Fig. 3 and Fig. 4 represent the different cumulative trends in function of L/S 307 for W1 and W2 respectively.

308 Here Figure 3.

309 Here Figure 4.

310

311 Analysing the trends over time, the effect of ambient conditions seems to not alter

312 the overall shape of the curves. Also in these cases the leaching behaviour was 313 characterized by a first phase of deep release of constituents and by a second phase 
314 characterized by low concentrations.

315 In order to compare the impact of ambient conditions on the leaching behaviour,

316 results were compared with the outcomes of the standard protocol (used as blank assay).

317 In particular the average concentration at $\mathrm{L} / \mathrm{S}=101 \cdot \mathrm{kg}^{-1} \mathrm{TS}$ was calculated for each of the

318 tested conditions and used as following, eq. 3:

$$
\Delta \rho_{10, X}=\frac{\rho_{10, X}-\rho_{10}}{\rho_{10}}
$$

319 where:

320

$321 \Delta \rho_{10, X}$ : variation of the average concentration of a component compared to blank assay

322 results. X represents C, T and A alternatively (\%);

$323 \rho_{10, X}$ : average concentration of a component calculated for the different ambient

324 conditions $\left(\mathrm{mg} \cdot 1^{-1}\right)$;

$325 \rho_{10}$ : average concentration of a component calculated for the blank assay $\left(\mathrm{mg} \cdot \mathrm{l}^{-1}\right)$.

326

327 Tab. 3 shows the percentage variation $\Delta \rho_{10}$ calculated for $\mathrm{C}, \mathrm{T}$ and $\mathrm{A}$ experiments in 328 comparison with the standard test.

329 Here table 3.

330

331 Evaluating $\Delta \rho_{10}$ results, acid environment showed a higher impact on $\mathrm{Cr}, \mathrm{Cu}$ and

332 chlorides for both W1 and W2. In the same way, the effect of mechanical constraint was 
333 mainly relevant for DOC and chlorides. For Ni the application of ambient conditions 334 reported different results for $\mathrm{W} 1$ and $\mathrm{W} 2$. Indeed while for $\mathrm{W} 1$ all the ambient 335 conditions reported an increase of average concentration, for W2 only the impact of 336 temperature reported a significant increase. Considering $\mathrm{Zn}$ and sulphates, the effect of 337 conservative conditions seemed to not alter their cumulative release at standard 338 conditions. Only for sulphates the effect of the acid environment produced an increase 339 of cumulative release for W2.

340 Principal Component Analysis (PCA) is increasingly used for experimental data 341 analysis on environmental topics to extract a small number of latent factors with the 342 intent of analysing the relationship among the observed variables (Singh et al., 2016).

343 While it is commonly used to identify the sources of pollution, in the present research 344 PCA was performed with the aim to deeply investigate the leaching behaviour of W1 345 and W2 in relation to the application of batch and column tests and regarding the 346 application of different ambient conditions. As such, the analysis was performed 347 considering 5 parameters: $\rho_{10}, \rho_{10, A}, \rho_{10, T}, \rho_{10, \mathrm{C}}$ and $\mathrm{c}_{10, \mathrm{~b}}$. In accordance with Kaiser 348 normalization, only the components with eigenvalue higher than 1 were considered as

349 relevant. In particular, the two principal components extracted accounted for $84.5 \%$ of 350 the total variance. The first component was dominated by high positive loading in DOC, $351 \mathrm{Ni}$ and sulphates $(0.967,0.855$ and 0.950 respectively) and a high negative loading in 352 chlorides and $\mathrm{Zn}(-0.829$ and -0.767 respectively). The second component had a strong 
353 positive loading only on $\mathrm{Cr}(0.840)$ and moderate positive loadings on $\mathrm{Cu}, \mathrm{Zn}$ and 354 chlorides. By comparing the different loadings and the score plot (Fig. 5) it was possible 355 to confirm the relationship between the different concentrations previously highlighted.

356 In particular, the tests performed on W1 were clustered together with the exception of 357 the outcome obtained for acid environment (W1- $\left.\rho_{10, A}\right)$. In this case its position on the 358 score plot was found far from the other dots representing the batch test and the other 359 ambient conditions. This result confirmed that the impact of mechanical constraint and 360 temperature do not affect the leaching behaviour while acid environment produces an 361 overall higher release of polluting substances. Here again, in the light of the score plot, it 362 can be noticed that there is no significant difference between standard column test and 363 batch test results $\left(\mathrm{W} 1-\rho_{10}, \mathrm{~W} 1-\mathrm{c}_{10, \mathrm{~b}}\right)$. This results was not evident for W2 since W2- $\rho_{10}$ 364 and W2- $\mathrm{c}_{10, \mathrm{~b}}$ dots were distant from each other reflecting what previously reported in 365 chapter 3.2 for W2. Even if with a lighter effect, also in this case the acid conditions 366 seemed to worsen the overall release of polluting substances. The score plot furthermore 367 confirmed that mechanical constraints and temperature do not impact the leaching 368 behaviour of W2 since their dots are placed in a free-component space.

369 Here Figure 5.

370

371 In order to assess the stability of waste, column leaching tests are viable tools to 372 investigate the changes of leaching behaviour over time under the effect of ambient 
373 conditions. With respect to WHPS, acid environment seems to accelerate the leaching 374 process resulting in a higher cumulative released quantity measured on a consistent

375 number of tested components. The harmful impact of an acid leachant is concurring 376 with main findings of Liu et al. (2013) who found an increase of phenol leaching for 377 solidified/stabilised hazardous waste under $\mathrm{pH}=4.9$. On the contrary, the effect of 378 temperature and mechanical constraint did not affect the process showing final contents 379 even lower than values found for blank assay.

\section{Conclusions}

382

383 The leaching behaviour of four WHPS samples was tested using two different 384 leaching tests: batch and column tests. The impact of ambient conditions such as 385 temperature, mechanical constraints and acid environment was also assessed performing

386 column tests. While temperature and mechanical constraint are impacts that commonly 387 occur inside the landfill body, it is interesting to study the effect of acid conditions since 388 it is a critical aspect that can accelerate the elution process.

389 Batch tests results showed good agreement with column test results in terms of 390 average concentration calculated at a liquid to solid ratio of $101 \cdot \mathrm{kg}^{-1} \mathrm{TS}$. As such, when 391 time is constraint in the decision-making process or when column tests are not 392 accessible, batch tests can be an optimum alternative for an overall indication. Despite 
393 this, column tests deeply assess the leaching behaviour of WHPS finding peak 394 concentrations in the early stages of the elution process that batch tests are not able to 395 show. Under this perspective column tests are viable tools to analyse the release of 396 constituents over time, in the short, medium and long term.

397 In the matter of evaluating the impact of ambient conditions, only the application of 398 acid environment seems to accelerate the leaching process of WHPS. In this case a 399 deeper mobilisation of the polluting substances was observed. This condition was 400 studied ad absurdum since alkaline condition are mostly present inside the landfill body. 401 On the contrary, the effect of temperature and mechanical constraint did not affect the 402 process showing final contents even lower than values found for the test performed at 403 standard conditions.

\section{Acknowledgements}

406

407 The authors want to thank the support of Pistoiambiente S.r.l. for providing the WHPS 408 samples.

409

410 References

411

412 Al-Abed, S.R., Jeegadeesan, G, Purandare, J., Allen, D., 2008. Leaching behaviour of 
413 mineral processing waste: comparison of batch and column investigations. J. Hazar. 414 Mater. 153, 1088-1092.

415 APAT, 2003. Metodi analitici per le acque, carbonio organico disciolto. APAT CNR $416 \quad$ IRSA 5040 Man 29, 2003.

417 APHA, 2006. Standard Methods for the Examination of Water and Wastewater, 418 eighteenth ed. American Public Health Association, Washington, DC.

419 Barna, R., Sanchez, F., Moszkowicz, P., Méhu, J., 1997. Leaching behavior polluttants 420 in stabilized/solidified wastes. J. Hazard Mater. 52, 287-310.

421 Batchelor, B., 2006. Overview of waste stabilization with cement. Waste manage. 26, $422 \quad 689-698$.

423 Beaven, R.P., 2000. The hydrogeological and geotechnical properties of household 424 waste in relation to sustainable landfilling. Department of Civil Engineering, Queen $425 \quad$ Mary and Westfield College, May 1999, Published January 2002.

426 Bin-Shafique, S., Benson, C.H., Edil, T.B., Hwang, K., 2006. Leachate concentrations 427 from water leach and column leach tests on fly ash-stabilised soils. Environ. Eng. Sci. $428 \quad 23(1), 53-67$.

429 Butcher, E.J., Cheesman, C.R., Sollars, C.J., Perry, R., 1996. Flow-through testing 430 applied to stabilized/solidified wastes. Stabilization and solidification of hazardous, 431 radioactive and mixed waste. ASTM STP 1240, 3, 355-374. 
432 Butera, S., Christensen, T.H., Astrup, T.F., 2014. Composition and leaching of 433 construction and demolition waste: inorganic elements and organic compounds. J. $434 \quad$ Hazard. Mater. 276, 302-311.

435 Butera, S., Hyks, J., Christensen, T.H., Astrup, T.F., 2015. Construction and demolition 436 waste: comparison of standard up-flow column and down-flow lysimeter leaching 437 tests. Waste manage. $43,386-397$.

438 CEN TS 14405, 2014. CEN TS 14405:2014 Characterization of Waste - Leaching 439 Behaviour test - Up-flow Percolation Test (Under Specified Conditions).

440 Cruz Payán, M., Galan, B., Coz, A., Vandecasteele, C., Viguri, J.R., 2012. Evaluation 441 through column leaching tests of metal release from contaminated estuarine sediment 442 subject to $\mathrm{CO}_{2}$ leakages from Carbon Capture and Storage sites. Environ. Pollut. 171, $443 \quad 174-184$.

444 De Windt, L., Badreddine, R., Lagneau, V., 2007. Long-term reactive transport 445 modelling of stabilized/solidified waste: from dynamic leaching tests to disposal 446 scenarios.

447 Delay, M., Lager, T., Schulz, H.D., Frimmel, F.H., 2007. Comparison of leaching tests 448 to determine and quantify the release of inorganic contaminants in demolition waste. 449 Waste manage. 27, 248-255.

450 Dijkstra, J.J., van der Sloot, H.A., Meeussen, J.C.L., Comans, R.N.J., 2006. Local 451 chemical equilibrium makes column test protocol TS14405 suitable for model 
452 predictions. In: WASCON 2006: Sixth International Conference on the 453 Environmental and technical Implications of Construction with Alternative Materials 454 Science and Engineering of Recycling for environmental Protection, Belgrade, 455 Serbia \& Montenegro.

456 Du, Y.-J., Jiang, N.-J., Shen, S.-L., Jin, F., 2012. Experimental investigation of 457 influence of acid rain on leaching and hydraulic characteristics of cement-based 458 solidified/stabilised lead contaminated clay. J. Hazard. Mater. 225-226, 195-201.

459 EN 12457-2, 2002. EN 12457-2:2002 Characterisation of Waste - Leaching 460 Compliance Test for Leaching of Granular Waste Materials and Sludges - Part 2.

461 EN 932-1, 1996. EN 932-1:1996 Test for General Properties of Aggregates - Methods 462 for Sampling - Part 1.

463 EPA, 2002. European Waste Catalogue and Hazardous Waste List - Valid form 1 464 January 2002. ISBN: 1-84095-083-8.

465 EPA 6020A, 2007. Inductively coupled plasma-mass spectrometry.

466 EPA 9056A, 2007. Determination of inorganic anions by ion chromatography.

467 European Council, 2002. European Council Decision 2003/33/EC of 19 December 2002 468 Establishing Criteria and Procedures for the Acceptance of Waste at Landfills 469 Pursuant to Article 16 of and Annex II to Directive 1999/31/Ec. EU.

470 Garrabrants, A.C., Kosson, D.S., 2005. Leaching processes and evaluation tests for 471 inorganic constituent release from cement-based matrices. In: Spence, R., Shi, C. 
472 (Eds.), Stabilisation and Solidification of Hazardous, Radioactive and Mixed Waste. 473 CRC Press, Boca raton, 229-280.

474 Gardner, K.H., Tsiatsios, C.J., Melton, J., Seager, T.P., 2007. Leaching behaviour of 475 estuarine sediments and cement-stabilized sediments in upland management 476 environments. Waste manage. 27, 1648-1654.

477 Harwell, S., 1999. Overview of current approaches. Proceedings of the Environmental 478 Protection Agency, Public meeting on waste leaching, Session III - Leaching $479 \quad$ Science.

480 Hartley, W., Edwards, R., Lepp, N.W., 2004. Arsenic and heavy metal mobility in iron 481 oxide-amended contaminated soils as evaluated by short- and long-term leaching 482 tests. Environ. Pollut. 131, 495-504.

483 ISPRA, 2015. Rapporto rifiuti speciali, Edizione 2015. ISPRA 226/2015. ISBN: 978$484 \quad 88-448-0732-0$.

485 Kalbe, U., Berger, W., Eckardt, J., Simon, F.G., 2008. Evaluation of leaching and 486 extraction procedures for soil and waste. Waste manage. 28, 1027-1058.

487 Liu, J., Nie, X., Zeng, X., Su, Z., 2013. Long-term leaching behavior of phenol in 488 cement/activated-carbon solidified/stabilized hazardous waste. J. Environ. Manage. $489 \quad 115,265-269$. 
490 Lopez Meza, S., Garrabrants, A.C., van der Sloot, H., Kosson, D.S., 2008. Comparison 491 of the release of constituents from granular materials under batch and column testing. $492 \quad$ Waste manage. 28, 1853-1867.

493 Malviya, R., Chaudhary, R., 2006. Leaching behaviour and immobilization of heavy 494 metals in solidified/stabilized products. J. Hazard. Mater. B137, 207-217.

495 Nielsen, P., Kenis, C., Quaghebeur, M., Hermans, M., 2006. Environmental quality 496 assessment of construction and demolition waste: comparison of percolation and 497 batch leaching tests. In: WASCON 2006: Sixth International Conference on the 498 Environmental and technical Implications of Construction with Alternative Materials 499 Science and Engineering of Recycling for environmental Protection, Belgrade, $500 \quad$ Serbia \& Montenegro.

501 Poon, C.S., Chen, Z.Q., 1999. Comparison of the characteristics of flow-through and 502 flow-around leaching tests of solidified heavy metal wastes. Chemosphere 38, 3, $503 \quad 663-680$.

504 Quaghebeur, M., Kenis, C., Nielsen, P., Tirez, K., Geysen, D., Dedecker, D., 2006. 505 Assessing the environmental quality of soils that are used in construction works: 506 comparison of column and batch tests in a regulatory context. In: WASCON 2006: 507 Sixth International Conference on the Environmental and technical Implications of 508 Construction with Alternative Materials Science and Engineering of Recycling for 509 environmental Protection, Belgrade, Serbia \& Montenegro. 
510 Raga, R., Cossu, R, 2013. Bioreactor tests preliminary to landfill in situ aeration: a case $511 \quad$ study. Waste manage. 33, 871-880.

512 Roussat, N., Méhu, J., Abdelghafour, M., Brula, P., 2008. Leaching behaviour of 513 hazardous demolition waste. Waste manage. 28, 2032-2040.

514 Simon, F.G., Kalbe, U., Berger, W., 2008. Characterization by leaching and extraction

515 procedures. GeoCongress 2008: Getechnics of Waste Management and remediation. $516 \quad$ New Orleans, March 9-12.

517 Shingh, S., Raju, N. J., Gossel, W., Wycisk, P. , 2016. Assessment of pollution potential 518 from the municipal solid waste disposal site and its impact on groundwater quality, 519 Varanasi environs, India. Arab. J. Geosci. 9 (131), 1-12.

520 Turner, A., Braungardt, C., Worsfold, P., Rieuwerts, J., Williamson, B., Potter, H., 521 2009. Dynamic up-flow percolation tests - a modeling for mining waste leachate 522 generation. Proceedings of the International Mine Water Conference, $19^{\text {th }}-23^{\text {rd }}$ 523 Ocotber 2009, Pretoria (SA), 858-867.

524 Wang, Y., Pelkonen, M., Kaila, J., 2012. Effects of temperature on the lon-term 525 behaviour of waste degradation, emissions and post-closure management based on 526 landfill simulators. The Open Waste Manage. J. 5, 19-27. 


\section{Highlights}

- The leaching behaviour of waste marked as hazardous partly stabilised is studied.

- Column and batch tests are performed and their results are compared.

- The impact of temperature, compaction and acid conditions are tested with column tests.

- Column results are comparable with batch results in terms of average concentration.

- Acid environment accelerates the leaching process. 


\section{Figure Captions}

Fig. 1. Cumulative release of $\mathrm{DOC}, \mathrm{Cr}, \mathrm{Cu}, \mathrm{Ni}, \mathrm{Zn}$, chlorides and sulphates in terms of $\mathrm{mg} \cdot \mathrm{kg}^{-1} \mathrm{TS}$ in function of L/S ratio for W1 (indicated by rhombus), W2 (squares), W3 (triangles) and W4 (circles). 
Fig. 2. Comparison between average concentration $\rho_{10}$ from column tests and measured concentrations in batch tests $\mathrm{c}_{10, \mathrm{~b}}$ at $\mathrm{L} / \mathrm{S}=101 \cdot \mathrm{kg}^{-1} \mathrm{TS}$. Four dots for each element are present in the graph representing each of the four samples tested. 
Fig. 3. Cumulative release of $\mathrm{DOC}, \mathrm{Cr}, \mathrm{Cu}, \mathrm{Ni}, \mathrm{Zn}$, chlorides and sulphates in terms of $\mathrm{mg}^{\mathrm{kg}} \mathrm{kg}^{-1} \mathrm{TS}$ in function of L/S ratio for W1. Standard conditions (W1) are represented by continuous line, mechanical constraint (W1-C) by dotted line, temperature (W1-T) by dash-dotted line, acid environment (W1-A) by dashed line. 
Fig. 4. Cumulative release of $\mathrm{DOC}, \mathrm{Cr}, \mathrm{Cu}, \mathrm{Ni}, \mathrm{Zn}$, chlorides and sulphates in terms of $\mathrm{mg}^{\mathrm{kg}} \mathrm{kg}^{-1} \mathrm{TS}$ in function of L/S ratio for W2. Standard conditions (W1) are represented by continuous line, mechanical constraint (W1-C) by dotted line, temperature (W1-T) by dash-dotted line, acid environment (W1-A) by dashed line. 
Fig. 5. PCA score plot. $\mathrm{W} 1$ parameters $\left(\mathrm{W} 1-\rho_{10}, \mathrm{~W} 1-\rho_{10, \mathrm{~A}}, \mathrm{~W} 1-\rho_{10, \mathrm{C}}, \mathrm{W} 1-\rho_{10, \mathrm{~T}}, \mathrm{~W} 1-\mathrm{c}, \mathrm{b}_{10}\right)$ are represented by rhombus while W2 parameters (W2- $\left.\rho_{10}, \mathrm{~W} 2-\rho_{10, \mathrm{~A}}, \mathrm{~W} 2-\rho_{10, \mathrm{C}}, \mathrm{W} 2-\rho_{10, \mathrm{~T}}, \mathrm{~W} 2-\mathrm{c}, \mathrm{b}_{10}\right)$ are represented by squares. 


\section{Figure 1}

Click here to download high resolution image
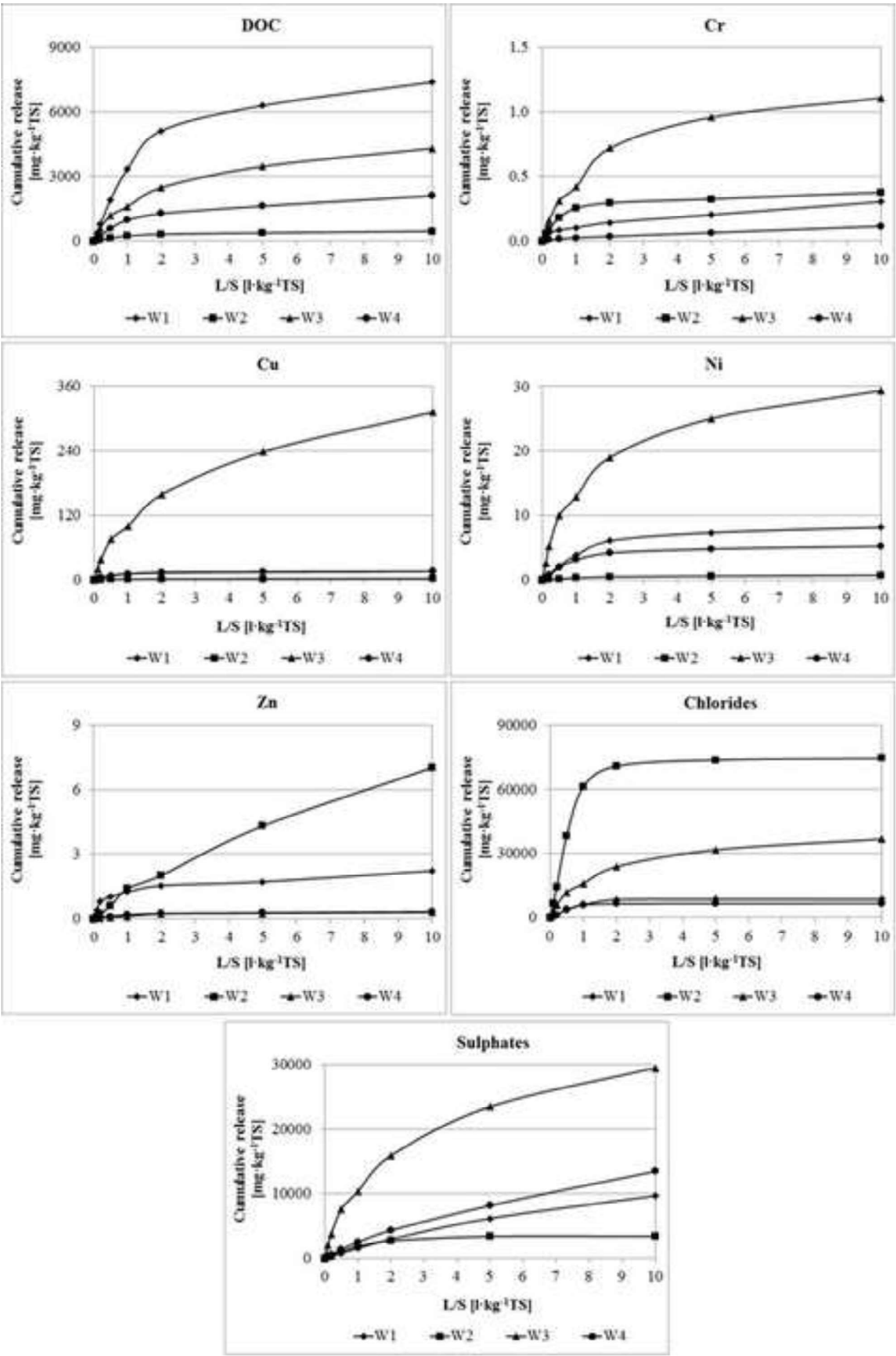
Figure 2

Click here to download high resolution image

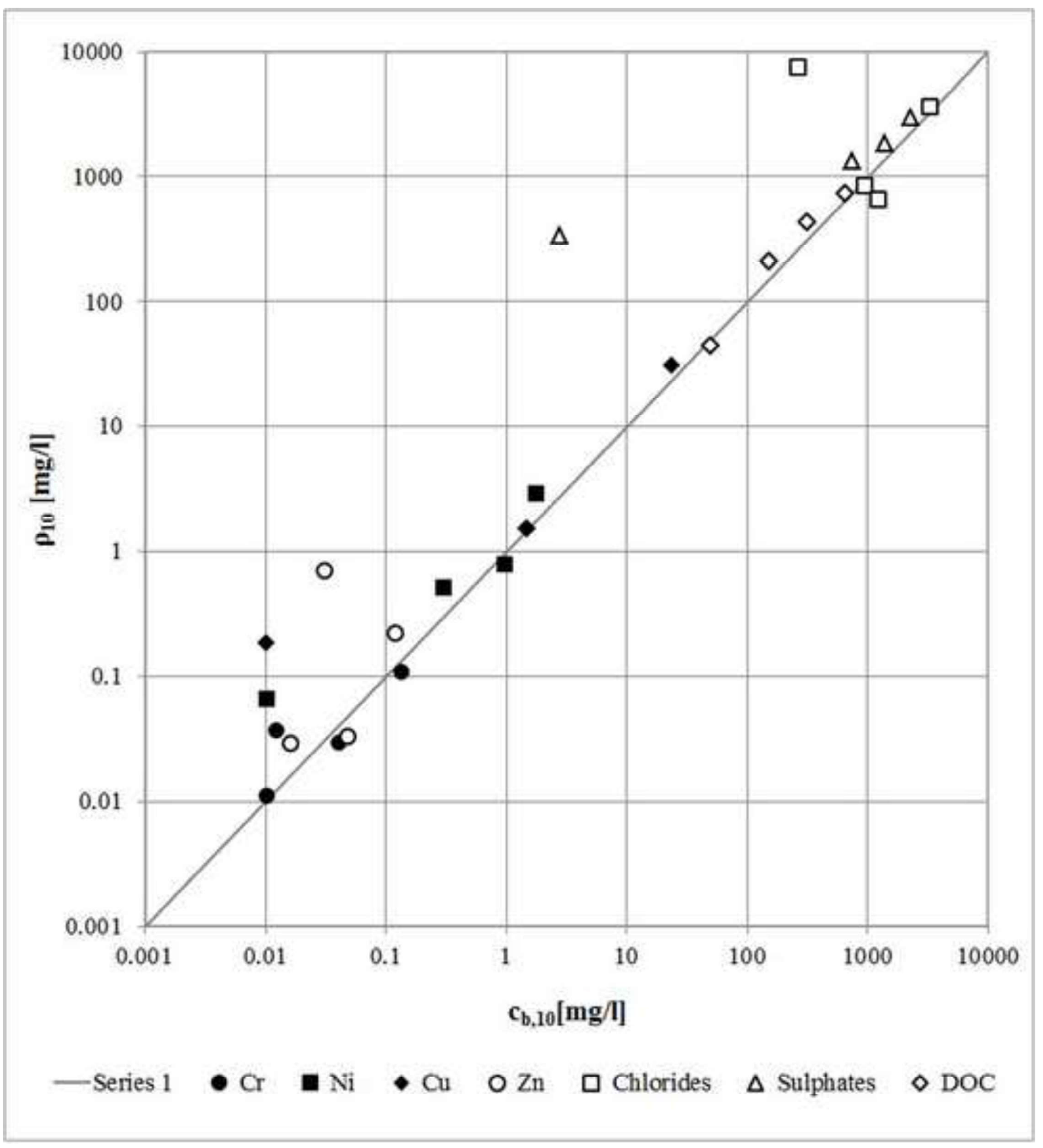


Figure 3

Click here to download high resolution image
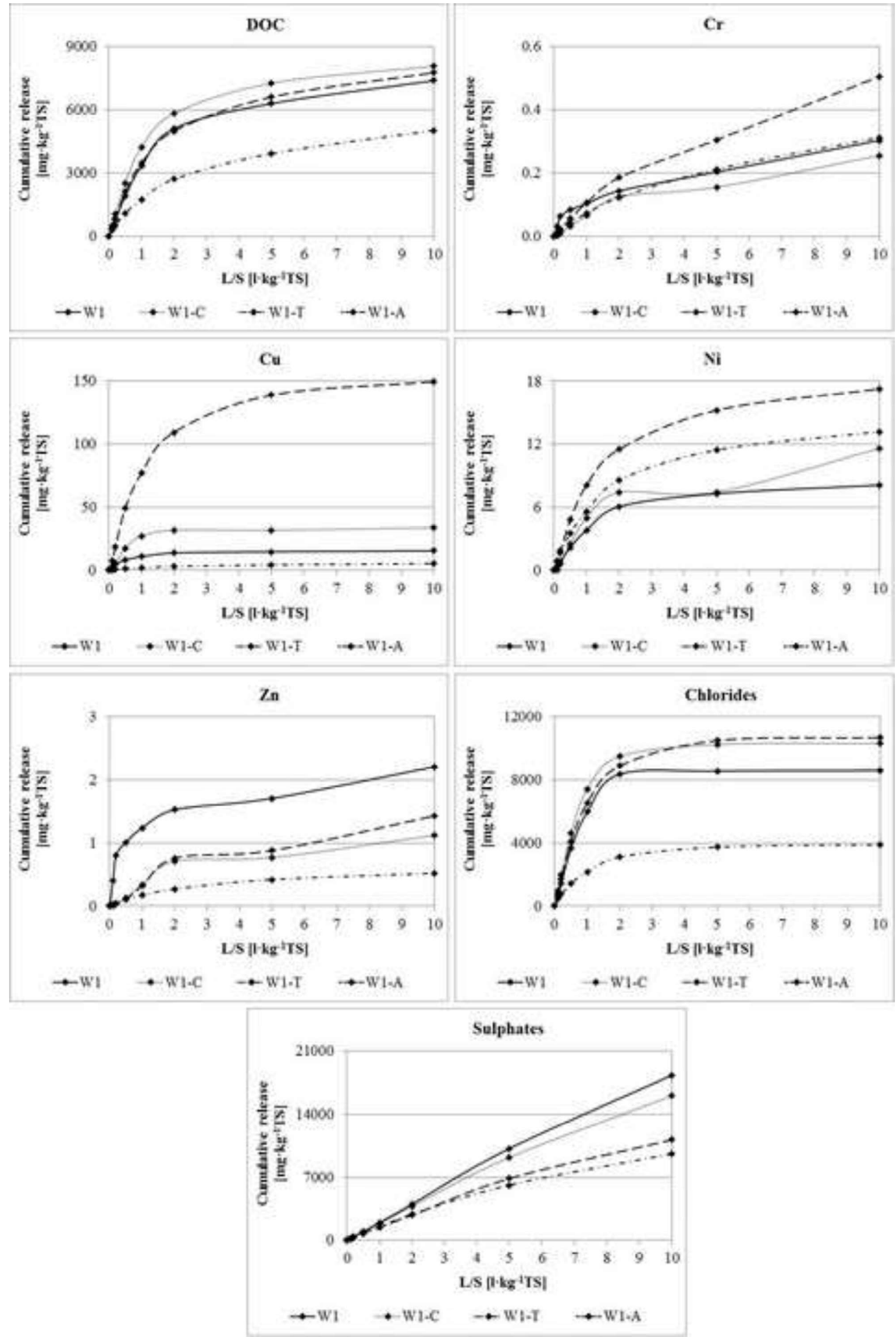
Figure 4

Click here to download high resolution image
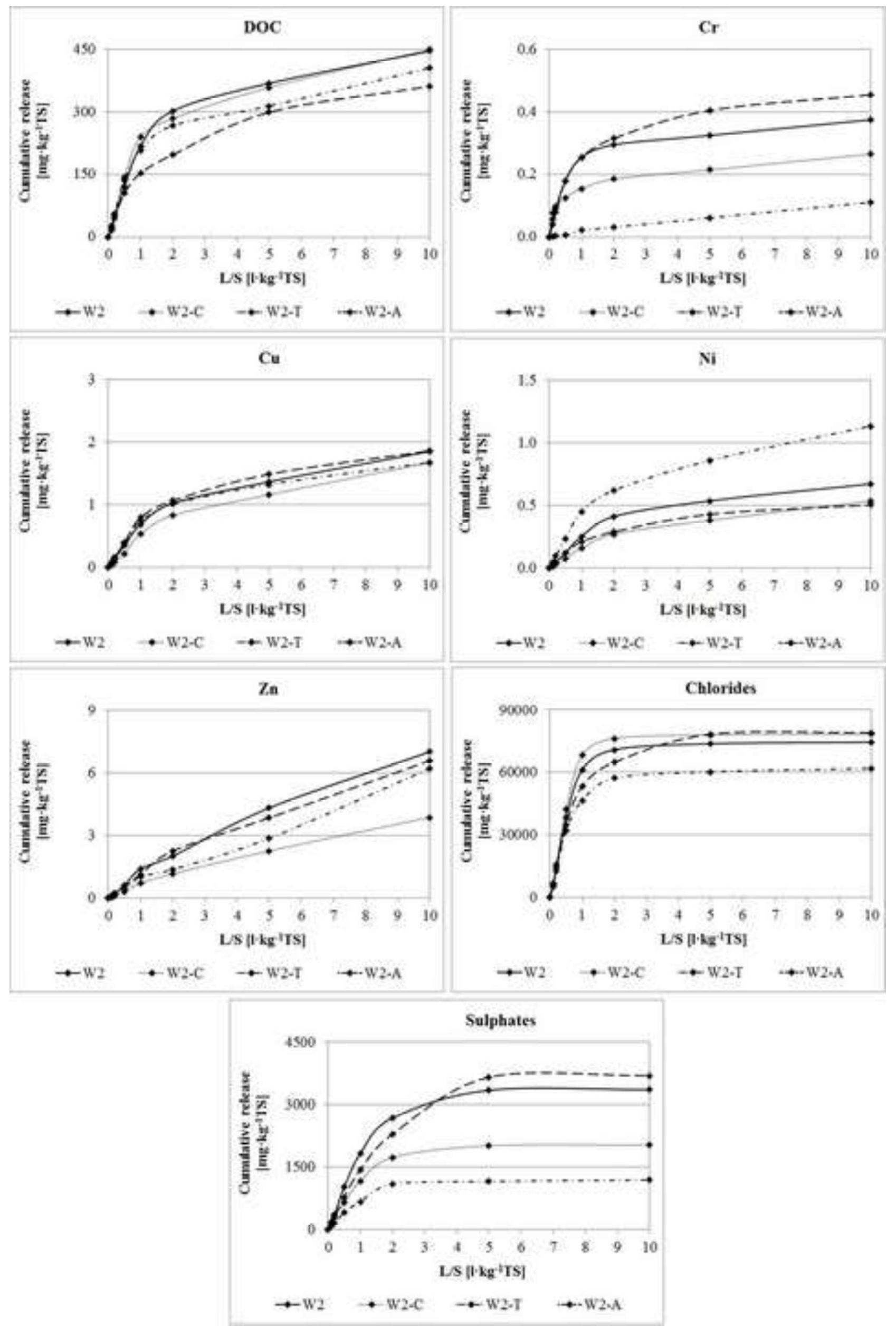


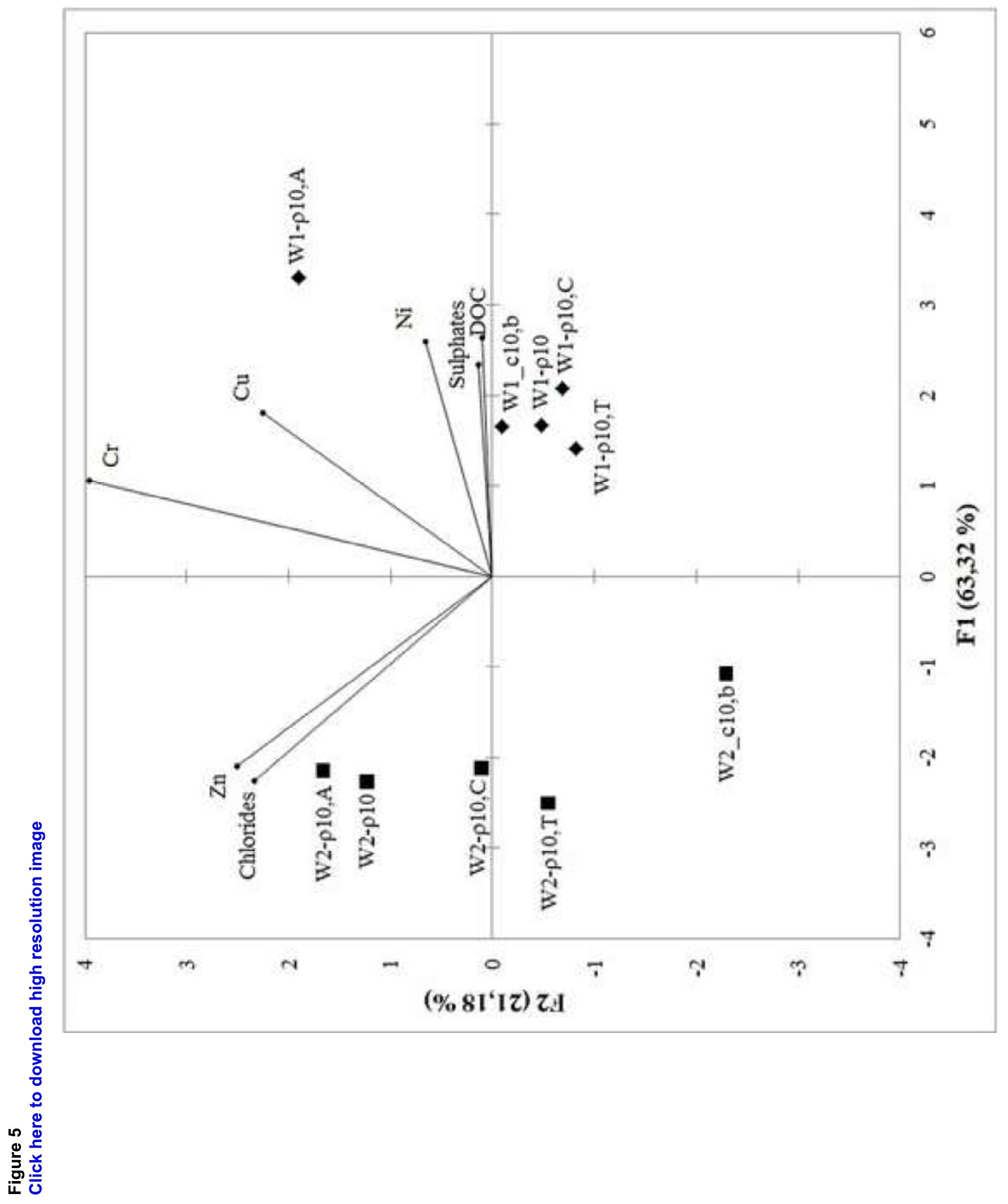




\section{Table 1}

Summary of the physico-chemical characteristics of the four samples studied (W1-W4).

\begin{tabular}{llcccc}
\hline Parameter & Unit & W1 & W2 & W3 & W4 \\
\hline Description & & Granular & Granular & Granular & Granular \\
Total Solids (TS) & $\%$ & 69.4 & 83.4 & 50.6 & 81.6 \\
Total Volatile Solids (TVS) & $\%$ & 25.2 & 1.8 & 14.5 & 21.7 \\
Total Organic Carbon (TOC) & $\%$ & 16.2 & 4.1 & 5.1 & 12.4 \\
pH & $\mathrm{pH} \mathrm{unit}$ & 9.1 & 13.1 & 11.2 & 9.5 \\
Cr & $\mathrm{mg} \cdot \mathrm{kg}^{-1} \mathrm{TS}$ & 390 & 78 & 3052 & 267 \\
Cu & $\mathrm{mg} \cdot \mathrm{kg}^{-1} \mathrm{TS}$ & 2457 & 7916 & 3437 & 2238 \\
Ni & $\mathrm{mg} \cdot \mathrm{kg}^{-1} \mathrm{TS}$ & 1767 & 36 & 2939 & 816 \\
Zn & $\mathrm{mg} \cdot \mathrm{kg}^{-1} \mathrm{TS}$ & 8235 & 10355 & 4115 & 19909 \\
Density & $\mathrm{kg} \cdot \mathrm{m}^{-3}$ & 912 & 1024 & 954 & 980 \\
Fraction $\geq \mathbf{1 0 ~} \mathbf{~ m m}$ & $\%$ & $<5$ & $<5$ & $<5$ & $<80$ \\
Fraction $<\mathbf{4 m}$ & $\%$ & $<80$ & $<80$ & $<80$ \\
\hline
\end{tabular}




\section{Table 2}

Comparison between the concentrations measured in the batch test $c_{10, b}$ and the average concentrations $\rho_{10}$ calculated for column testing. The two concentrations are compared in terms of ratio and Welch t-test (values are not statistically different when $\mathrm{p}>0.05$ ). The inverse ratio is indicated in brackets. Data are emphasized in italics to underline that results from one of the two concentrations is below LOD $\left(0.01 \mathrm{mg} \cdot 1^{-1}\right.$ for metals $)$ and that the comparison should be regarded in a qualitative way.

\begin{tabular}{|c|c|c|c|c|c|c|c|c|c|c|c|c|c|}
\hline & \multicolumn{3}{|c|}{ W1 } & \multicolumn{3}{|c|}{ W2 } & \multicolumn{3}{|c|}{ W3 } & \multicolumn{3}{|c|}{ W4 } & \\
\hline & $\mathrm{c}_{10, \mathrm{~b}}$ & $\rho_{10}$ & $\begin{array}{c}\mathrm{c}_{10, \mathrm{~b}} / \\
\rho_{10}\end{array}$ & $\mathrm{c}_{10, \mathrm{~b}}$ & $\rho_{10}$ & $\begin{array}{c}\mathrm{c}_{10, \mathrm{~b}} / \\
\rho_{10}\end{array}$ & $\mathrm{c}_{10, \mathrm{~b}}$ & $\rho_{10}$ & $\begin{array}{c}\mathrm{c}_{10, \mathrm{~b}} / \\
\rho_{10}\end{array}$ & $\mathrm{c}_{10, \mathrm{~b}}$ & $\rho_{10}$ & $\begin{array}{c}\mathrm{c}_{10, \mathrm{~b}} / \\
\rho_{10}\end{array}$ & \\
\hline Unit & $\mathrm{mg} \cdot \mathrm{l}^{-1}$ & $\mathrm{mg} \cdot \mathrm{l}^{-1}$ & $\mathrm{n}$ & $\mathrm{mg} \cdot \mathrm{l}^{-1}$ & $\mathrm{mg} \cdot \mathrm{l}^{-1}$ & $\mathrm{n}$ & $\mathrm{mg} \cdot \mathrm{l}^{-1}$ & $\mathrm{mg} \cdot \mathrm{l}^{-1}$ & $\mathrm{n}$ & $\mathrm{mg} \cdot \mathrm{l}^{-1}$ & $\mathrm{mg} \cdot \mathrm{l}^{-1}$ & $\mathrm{n}$ & $\begin{array}{c}\text { Welch } \\
\text { t-test }\end{array}$ \\
\hline DOC & 656 & 738 & $\begin{array}{c}0.9 \\
(1.1)\end{array}$ & 50 & 45 & $\begin{array}{c}1.1 \\
(0.9)\end{array}$ & 316 & 429 & $\begin{array}{c}0.7 \\
(1.4)\end{array}$ & 152 & 210 & $\begin{array}{c}0.7 \\
(1.4)\end{array}$ & 0.38 \\
\hline $\mathrm{Cr}$ & 0.04 & 0.03 & $\begin{array}{c}1.3 \\
(0.8)\end{array}$ & 0.01 & 0.04 & $\begin{array}{c}0.3 \\
(3.1)\end{array}$ & 0.13 & 0.11 & $\begin{array}{c}1.2 \\
(0.8)\end{array}$ & 0.01 & 0.01 & $\begin{array}{c}0.9 \\
(1.1)\end{array}$ & 0.50 \\
\hline $\mathrm{Cu}$ & 1.47 & 1.54 & $\begin{array}{c}1.0 \\
(1.0)\end{array}$ & $<0.01$ & 0.18 & $\begin{array}{c}0.1 \\
(18.5)\end{array}$ & 23.72 & 31.16 & $\begin{array}{c}0.8 \\
(1.3)\end{array}$ & 1.49 & 1.53 & $\begin{array}{c}1.0 \\
(1.0)\end{array}$ & 0.42 \\
\hline $\mathrm{Ni}$ & 0.96 & 0.81 & $\begin{array}{c}1.2 \\
(0.8)\end{array}$ & $<0.01$ & 0.07 & $\begin{array}{c}0.1 \\
(6.7)\end{array}$ & 1.75 & 2.93 & $\begin{array}{c}0.6 \\
(1.7)\end{array}$ & 0.30 & 0.52 & $\begin{array}{c}0.6 \\
(1.7)\end{array}$ & 0.34 \\
\hline $\mathrm{Zn}$ & 0.12 & 0.22 & $\begin{array}{c}0.5 \\
(1.8)\end{array}$ & 0.03 & 0.70 & $\begin{array}{c}0.0 \\
(22.6)\end{array}$ & 0.02 & 0.03 & $\begin{array}{c}0.5 \\
(1.8)\end{array}$ & 0.05 & 0.03 & $\begin{array}{c}1.5 \\
(0.7)\end{array}$ & 0.16 \\
\hline Chlorides & 939 & 859 & $\begin{array}{c}1.1 \\
(0.9)\end{array}$ & 265 & 7441 & $\begin{array}{c}0.0 \\
(28.1)\end{array}$ & 3329 & 3668 & $\begin{array}{c}0.9 \\
(1.1)\end{array}$ & 1228 & 666 & $\begin{array}{l}1.8 \\
(0.5)\end{array}$ & 0.19 \\
\hline Sulphates & 1388 & 1832 & $\begin{array}{c}0.8 \\
(1.3)\end{array}$ & 3 & 335 & $\begin{array}{c}0.0 \\
(119.7)\end{array}$ & 2277 & 2948 & $\begin{array}{c}0.8 \\
(1.3)\end{array}$ & 746 & 1345 & $\begin{array}{c}0.6 \\
(1.8)\end{array}$ & 0.25 \\
\hline
\end{tabular}


Table 3

Variation of the average concentration $\Delta \rho_{10}$ between ambient conditions and the application of the standard test. C, A and T represent the impact of mechanical constraint, acid environment and temperature respectively. (-) means negative data.

\begin{tabular}{l|ccc|ccc}
\hline & \multicolumn{3}{|c|}{$\mathrm{W} 1$} & \multicolumn{3}{c}{$\mathrm{W} 2$} \\
\hline $\mathrm{DOC}$ & $\Delta \rho_{10, \mathrm{C}}[\%]$ & $\Delta \rho_{10, \mathrm{~A}}[\%]$ & $\rho_{10, \mathrm{~T}}[\%]$ & $\Delta \rho_{10, \mathrm{C}}[\%]$ & $\Delta \rho_{10, \mathrm{~A}}[\%]$ & $\Delta \rho_{10, \mathrm{~T}}[\%]$ \\
$\mathrm{Cr}$ & $9 \%$ & $5 \%$ & - & $1 \%$ & - & - \\
$\mathrm{Cu}$ & - & $67 \%$ & $3 \%$ & - & $21 \%$ & - \\
$\mathrm{Ni}$ & $118 \%$ & $876 \%$ & - & - & $1 \%$ & - \\
$\mathrm{Zn}$ & $43 \%$ & $113 \%$ & $63 \%$ & - & - & $69 \%$ \\
Chlorides & - & - & - & - & - & - \\
Sulphates & $20 \%$ & $24 \%$ & - & $5 \%$ & $6 \%$ & - \\
\hline
\end{tabular}

